\title{
Transformations of Efficient Market Hypothesis under the Influence of Behavioral Finance
}

\author{
Jekaterina Kartašova
}

Mykolas Romeris University, Ateities str. 20, Vilnius, Lithuania,

jkartasova@gmail.com

\section{Rita Remeikiene}

Kaunas University of Technology, Laisves str. 55, Kaunas, Lithuania rita.remeikiene@ktu.It

\section{Ligita Gaspareniene}

Mykolas Romeris University, Ateities str. 20, Vilnius, Lithuania, ligita.vasiliauskiene@ktu.It

\section{Deimantë Venclauskienè}

Kaunas University of Technology, Laisves str. 55, Kaunas, deimante.venclauskiene@ktu.It

\section{Doi:10.5901/mjss.2014.v5n13p327}

\section{Abstract}

The paper provides a theoretical study on efficient market hypothesis (EMH) changes under the influence of behavioral finance. Authors of the paper briefly provide the basic assumptions of efficient markets theory and remind how the top of its dominance was reached in the 1970s. At the same time the goal of the paper is to develop the unbiased and complex overview of the today's market efficiency and show its transformations under the impact of market participants' irrationality. In the paper authors introduce the interaction between market efficiency, market arbitrage, irrationality of market participants and highlight the importance to revise the reliability of efficient market theory assumptions in order to achieve high performance of investment portfolios. Through the behavioral finance point of view authors not only aggregate the critics EMH faces during the recent years, but also evaluate today's opportunities for arbitrage and provide arbitrage critics. According to documented by experimental economists departures from market efficiency and taking into consideration their nature, i.e. investors' irrationality as a result of influence of a set of specific behavioral (both cognitive and emotional) biases, an alternative to EMH approach called "The Adaptive Markets Hypothesis" espoused by Andrew Lo in 2004 is introduced. The supporters of the EMH have responded to these challenges by arguing that, while behavioral biases and corresponding inefficiencies do exist from time to time, there is a limit to their prevalence and impact because of opposing forces dedicated to exploiting such opportunities. Finally, basic financial market anomalies are presented in the paper as an example of market inefficiency. On the one hand, their persistence in the face of public scrutiny seems to be a clear violation of the EMH. On the other - most of these anomalies can be exploited by relatively simple trading strategies, and, while the resulting profits may not be riskless, they seem usually profitable relative to their risks. Summing up of the investigation presented in the paper, authors conclude that many classical EMH supporters set the cases theoretically without empirical or real measurement analysis. Therefore the discussion on EMH is still on-going, but real market analysis should be done instead of evolving EMH theoretical evaluation models, which remain theoretical and do not always work properly in the conditions of real financial market.

Keywords: Efficient market hypothesis, behavioral finance, financial market anomalies, adaptive market hypothesis, cognitive and emotional biases, financial market efficiency

\section{Introduction}

The efficient market hypothesis is one of the most important paradigms in modern finance and was largely accepted to hold by the early 1970s. In 1978, Michael Jensen declared his belief that "there is no other proposition in economics which has more solid empirical evidence supporting it." The main proposition of Efficient Market Hypothesis suggests that all relevant information is known and factored into the current price of stocks. The EMH implies that any new information has been factored into the price before an investor can learn of the information and act on it. So, what the theory has said 
for years is that there really is no true stock price anomaly that an investor can reasonably take advantage of.

The EMH has three levels: the weak form EMH, semi-strong form EMH and strong form EMH. Weak form of EMH - prices of asset reflects all past information which is available to the public; semi-strong form EMH - prices reflect all information available to the public and instantly change to show new information to public; and strong form EMH claims that prices show hidden an unreachable for the public information.

There are opinions and researches carried out (book: A Random Walk Down Wall Street) which explains and objects to EMH by saying that for example picking stocks is really no better than a chance. It is mentioned that random selection of stocks has the same likelihood to perform good as the research carried out looking for investment. Furthermore, taking into account main ideas of EMH (mentioned above) we should understand that it is not entirely correct. If the ideas of EMH were true there should not be "bubbles" in the market, long term opportunities for arbitrage and no rapid crashes. This also explains that if markets were efficient there should be no sudden fluctuation in prices for no reason.

Other assumption for EMH is that investors cannot outperform the market. There were examples when the market was actually outperformed by investors like George Soros, Warren Buffett of Peter Lynch. However, EMH doesn't imply that investors are unable to outperform the market. It is known that changes in information make prices fluctuate and it would be possible for an investor to "make killing" if a released information causes a huge increase in price of security investor owns. In this case EMH claims that one should not be expected to outperform market predictably or consistently. Even more, this attempt to deny the EMH could be explained like an example about lottery in which the probability of a given individual winning is virtually zero, but the probability that someone will win is very high. So mentioned successful investors like Soros, Buffet and Lynch is an expected outcome in a completely random distribution of investors. Theory would be denied and threatened if you could identify who those successful investors would be prior to their performance, rather than after the fact.

Another argument against EMH was for its statement that financial analysis is pointless and investors should not wais their time for price research. It is suggested that financial analysts and their service are valued in the financial markets so EMH must be incorrect. To support EMH we can explain that investors have different styles and taste what to buy or where to invest. Once like higher risk, others prefer less risky investment strategies. By expressing their preferences an optimal portfolio is created, a combination of return and risk which investor finds desirable. By randomly choosing portfolio this combination could not be fulfilled. Secondly, financial analysis is far from pointless in efficient markets. The competition among investors by seeking and analyzing the newest information in the market is the goal to take advantage of miss-priced stocks. This is also essential for the existence of efficient capital markets. The reason why every investor doesn't use financial analysis is because it is very expensive. As discussed previously financial analysts have to be able to collect, analyze, evaluate and process huge amounts of information about industries, changes in scientific discoveries, economy and so on. It requires a lot of time and effort in sophisticated analysis, as well as resources into data gathering, software and computers. In addition there exist transaction costs for those analysts who frequently trade securities.

This means that all the profits received from trading miss-priced stocks have to be reduced by the amount of financial analysis and transaction costs. The upshot is that there should be as many financial analysts in the market as optimal to insure that research and transaction costs are covered by the achieved gross trading profits. So for other investor chasing miss-priced stocks would be pointless because of the costs and lack of profit.

EMH claims that new information is always fully reflected in market prices. This assumption has also had some negative argument toward it claiming that prices fluctuate and change every day, hour and even minute meaning that EMH assumption is incorrect. However, this is not entirely correct because fluctuation of market prices can be assumed as indication that markets are efficient. New information always causes price to change and no change in prices would signal an inconsistency in the markets, since new information is arriving nearly continuously.

EMH presumes that all investors have to be skilled, informed and be able to constantly analyze the flow of new information. This assumption had been criticized that not ever investor is able to perform appropriate analysis of new information or follow every event. The criticism is however incorrect, because market efficiency can be achieved even if only a small group of informed and skilled investors trade in the market, while the rest of the investors never follow the securities which they trade.

\section{Informational Efficiency and Arbitrage}

The main concept of the financial theory is the arbitrage, which briefly consists of taking a position which isn't risky and making profit. For the neoclassical theory, the equilibrium of the market is incompatible with the arbitrage. In fact, the 
hypothesis which claim that people prefer to be more rich than less is enough to understand, because with that supposition, even a little opportunity of arbitrage will be used by everybody and without limit because it offers to you profit without risk. Thereby with the hypothesis of no arbitrage the neoclassical finance have for central result point "the price of any asset is the expected value of its payments for a single probability distribution" (Kast and Lapied).

One of the main consequences is the well-known efficient market hypothesis that origin can be found with Fama (1965). This efficiency has an informational nature and we will say that there is efficiency when the price reflected the whole information available (Fama, 1970). But some authors like Ross say that this formulation isn't so clear because of differences in interpretation, that could be grouped as following:

- The first define an efficiency market as being a market where all the financial assets financial are assessed correctly, given the information available at the time considered. This interpretation is due to Fama.

- The second emphasizes the non-predictability of the return. It means thanks to Ross "the returns on financial assets are very close to being serially uncorrelated and are almost statistically unpredictable". It deals with the abnormalities defined by Malkiel like "statistically significant predictable patterns in returns

- The third definition treats with the possibility to beat the market like Malkiel wrote "financial markets are efficient because they do not allow investors to earn above-average risk adjusted returns".

Obviously those three interpretations are linked but we won't develop it there. We can just say that the second comes from the first and the third comes from the second but the contrary isn't true. The third is considered by the neoclassical theory to be the main definition of an efficiency market. Indeed, for them it is not necessary just to find some econometrics predictabilities to claim that the market is inefficient. Or at least those predictabilities have to be enough important because of the transactions costs. For instance, Ross said "These anomalies are generally small which is to say they do not involve many dollars in comparison with the size of the capital markets and are not scalable".

After this brief reminder, we will see what the neoclassical actors advocate concerning the rationality of the actors in order to have an efficiency on the market.

\section{Irrationality and Critics about Arbitrage}

If all the actors are rational, the efficiency is obvious because everybody is able to evaluate correctly the assets, no one digress from the right price. But as we see the market daily, we know that some actors are not rational at all. For the neoclassical authors this is not a matter till a majority become irrational, Markiel told "Markets can be efficient even if many markets participants are quite irrational" and Ross add "The central themes of Neoclassical finance is not based on the rationality of the average person". In this context we may wonder how the market can be still efficient even if there are irrational actors. There is two cases to analyze, the first concerns the situation where the irrational decisions are made by independent actors and in this case all the irrationality decision are compensating each other, there is no need for any rational investors intervention. The other case in when there is a correlation between the irrational actions. Even in this case the efficiency will still be thanks to the arbitrage. In fact, the rational arbitrageurs will buy under-evaluated assets and sell over-evaluated one, like this the price will be back to its right position. Moreover, like Friedman said, the irrational actors are going to disappear from the market because they are losing money when they are buying over-evaluated assets or selling under-evaluated one.

That correlation of "irrationalities" is mainly the heart of the way if thinking of the behavioral finance. Even the terms "Noise Trader Approach" came from that, the "Noise Traders" are investors who have non-rational anticipations, who use wrong signals to act or who follow some irrationals strategic rules like the "popular model" from Shiller (1990). More precisely, the NTA is interested in market configurations in which the ignorant or irrational behavior are monitored simultaneously by a large number of investors (hypothesis of correlation) so that their impact on prices is effective and does not vanish unlike mechanically the error pattern uncorrelated.

After this correlation hypothesis made, the behavioral finance also contests the neoclassical vision which claim that the arbitrage is the only thing able to erase the movement of the prices due to some irrational behavior. The behavioral finance adds that the real arbitrage which is present in real market has a dimension of risk, to argue we can mention Shleifer (2000) "The central argument of behavioral finance states that, in contrast to the efficient markets theory, realworldarbitrage is risky and therefore limited". The pros of the behavioral finance argue that Neoclassical made the hypothesis that assets and portfolio are perfectly substitutable. But for example the market portfolio which contains all the listed shares has no substitutes. To emphasize its arguments, behavioral finance will say that even if we can find some substitutes, there still is a risk. We won't develop the arguments, we will just say that the proof comes from the error of evaluation relating to the arbitrage can continue and increase. To show it, Shleifer and Summers (in 1990) used the example of the Japanese shares in the eighties before the bubble burst. This example shows how the market can remain 
illogical far longer than we are able to remain solvent.

The implications of this analysis are fundamental because "risky arbitrage" means arbitration limited when one takes into account the risk aversion of investors. It follows that the rational arbitrageurs cannot totally eliminate pricing errors. Efficiency is lost even in the case of perfect substitutes.

So with those two hypotheses, the investors are not totally rational and the arbitrage is risky and so limited, the market stop to be efficient. With the action of the irrational investors the price can deviate for a long time from its normal position and even the rational arbitrageurs can't put it back. This leads to a profound transformation of the nature of financial rationality. Indeed, it follows from this analysis that the financial rationality can't be limited only to the observation of the fundamentals. The opinion of the ignorant is now a variable which is important since prices remain permanently footprint. This is the strategic behavior stock which is therefore considered by behavioral finance. In this way, the rational investor, also called "smart money" represent an investor which not only knows the fundamentals but also take into account how the various groups of actors in the market react to price changes and influence them.

To understand this new conception, we can just remind the model of De Long, Shleifer, Summers and Waldmann (1990) which deals with some rational investors against the "positive feedback traders". The positive feedback traders buy when they see an uptrend and sell in the case of a downtrend. These authors show that the presence of rational is destabilizing: it tends to increase the difference between the market price and the fundamental value of the security in question. Because rational wants to maximize their profits, and so they have an interest in stimulate mispricing hunters.

From the presentation of the current state in the presence of different theories, now let's analyze how their confrontation is structure and how the behavioral finance leads to a new basis for the financial market. The Efficient Market Hypothesis suggests that "if the flow of information is unimpeded and information is immediately reflected in stock prices, then tomorrow's price change will reflect only tomorrow's news and will be independent of the price changes today" (Malkiel, 2003). This statement implies that any information or knowledge that was gained previous to the current day is irrelevant to the current price change, because the historical knowledge is already in the historical prices. Many economists and behavioural specialists of the twenty- first century have criticised this notion saying, that stock prices are at least partially predictable as they are influenced not only by the current information and events, but also by the psychological and behavioural elements of stock buyers and sellers, past information about the changes in stock prices and fundamental analysis of companies financial statements. In this part of the article we will introduce different views on this matter suggested by economists and behaviour specialists and to conclude we will present our thoughts about the notion.

The most enduring critiques of the Efficient Market Hypothesis revolve around the preferences and behavior of market participants. These critics of the EMH argue that investors are often irrational and predictable. Behavioral studies of market participants have proven that individuals tend to be risk averse in the face of gains and risk seeking in the face of losses and that can lead to some irrational financial decisions. Market participants predictability can also be proven by the so called "bandwagon effect". This effect describes the situation in the market when market participants are drawn to a certain stocks because they see the increase in the price of those stocks. This effect can let an analyst of the stock market to speculate the increase or a decrease of demand for a certain stock. Another pattern that market participants follow is an under reaction to the new information. The full impact of an important announcement is only grasped over a period of time, so the time period before information reaches its full effect can be left for speculation. After analyzing these simple notions we can partially predict the behavior of market participants and imply that their behavior is not always rational.

The EMH also implies that past information and events cannot be used to predict future prices in any meaningful way as they are only historical data. Min Deng in his book "Death of The Efficient Market Hypotheses" states $: "<\ldots>$ research has also demonstrated that, normally, a 5-year-long stock price historical sequence with the transaction day as the time interval contains all the patterns of the stock price movement."(Deng, 2007). Many statisticians agree that stock price patterns exist and after difficult scientific research can be found in historical stock price data. Min Deng also states that such patterns as long-term reversal pattern or short-term momentum pattern can be found in "all the historical data sequences of any one single stock market all over the world."(Deng, 2007). Investors can use the existing patterns as a tool in portfolio management. But it is necessary to mention that stock patterns can be distorted by the investors themselves. If stock traders follow the same pattern they can commonly drive a stock price higher or lower than the stock fundamentals dictate. So the existence of stock price patterns proves that stock prices can be at least partially predicted but this does not mean that these patterns should be used as the main tool in portfolio management as they are only theoretical.

Certain fundamental valuation metrics can also be used to predict the future price of stocks. Fundamental analysiswhich is the analysis of financial information such as earnings or assets of a company can help investors select 
undervalued or spot overvalued stocks in their portfolio or in the market. Such fundamental values of a financial statement as earnings or dividends can be an indicator of stock price changes. It is commonly known that investors make their decisions in order to make profit. They make profit due to positive changes in stock prices or due to paid dividends, because of that, the increase in paid dividends would increase the interest in a certain stock and a decrease would do the opposite. In the case of comparing two sellable stocks, with other factors considered as being equal, a buyer would buy the stocks of that company that pays higher dividends. Furthermore, such ratios as debt to equity ratio or return or equity ratio can also be an indicator weather or not investors are going to be willing to buy certain stocks. So we can say that fundamental analysis of a financial statemens of a company ca be seen as a third possible tool to predict stock prices.

Stock price predictability as every other Efficient Market Hypothesis critique has its supporters and skeptics. The leading proponent of Efficient Markets Hypothesis Burton G. Malkiel argues that: "The strongest evidence suggesting that markets are generally quite efficient is that professional investors do not beat the market... If prices were often irrational and if market returns were as predictable as some critics of the efficient market hypothesis believe, than surely actively managed investment funds should easily be able to outdistance a passive index that simply buys and holds the market portfolio"(Deng, 2007). But as we previously discussed there are a couple of cases when professional investor do outperform the market, so we can argue that stock market unpredictability is no longer a rule without exceptions.

For as much as experimental economists documented a number of departures from market efficiency because of investors' irrationality in the form of specific behavioral biases, an alternative to the EMH that reconciles the latter with its behavioral critics called "The Adaptive Markets Hypothesis" (AMH) was espoused by Andrew Lo (2004).

Lo (2005) revisits the idea of "bounded rationality" first introduced by Herbert Simon (1955) that investors make choices that are mainly satisfactory, but not necessarily optimal, i.e. humans are naturally bounded in their degree of rationality, arguing that an evolutionary perspective is missing. With reference to Lo (2004) the points at which the optimizing behavior of individuals is satisfactory are determined through natural selection from an evolutionary perspective. Particular choices are based on past experience and "best guess" of investors as to what might be optimal and so that they generally learn by receiving either positive or negative reinforcement from their outcomes, thus in such a manner investors develop heuristics to solve various economic challenges, that gradually yield approximately optimal solutions if the economic environment does not change. However, if alterations exist, these particular heuristics no longer suit to the new environment and behavioral biases, i.e. obviously ill-advised actions, can be observed. Lo (2004) labels such a behavior as "maladaptive" rather than defining it as "irrational" since sub-optimal behavior is not unlikely when heuristics are taken out of evolutionary context.

By coupling bounded rationality and satisfaction, the $\mathrm{AMH}$ as the version of the EMH has been derived from evolutionary perspective and contains the following:

1. "Individuals act in their own self interest;

2. Individuals make mistakes;

3. Individuals learn and adapt;

4. Competition drives adaptation and innovation;

5. Natural selection shapes market ecology;

6. Evolution determines markets dynamics" (Lo, 2005).

With reference to Lo (2004), market dynamics is exactly the total sum of selfish individuals, competition, adaptation, natural selection and environmental conditions. In regard to the EMH, investors in efficient markets do not make any mistakes, furthermore any learning or adaptation occurs there, as such a market is unvarying, thus always in equilibrium, while according to the $\mathrm{AMH}$ approach mistakes are frequent, but investors learn from them and adapt their economic behavior accordingly, thus the convergence to equilibrium is not likely to occur at any point in time. It should be recognized that adaptation is believed to be driven by competition as opposed to occurring independently of market forces, in other words, the push for survival, thus the particular market environment is determined by the process of natural selection through the interactions among market participants, i.e. the survival of the richest in this context, while unsuccessful traders are eventually eliminated after suffering a certain number of losses. Greed and fear are defined as the product of evolutionary forces according to the $\mathrm{AMH}$ as well, in contrast to behaviorists' point of view defining them as the two main reasons in the downfall of rational thinking (Lo, 2004).

In regard to the $\mathrm{AMH}$, behavioral biases abound only because of heuristics adapted to non-financial context. The particular impact is determined by the size of the population with such behavioral biases compared to the size of competing populations with significantly more effective heuristics. As an instance, in the Fall of 1998, the desire for both liquidity and safety by certain investors significantly overwhelmed the population of hedge funds attempting to arbitrage such preferences, and hence entailed these particular arbitrage relations to break down, whereas untill August 1998 fixed-income relative-value traders profited abundantly from such activities, probably at the expense of investor with 
seemingly "irrational" preferences (Lo, 2005). Such preferences are mostly determined by a particular evolutionary forces, and probably might have been rational enough in other circumstances. To conclude according to the AMH, investment strategies undergo cycles of profitability and loss because of, firstly, volatile business conditions, secondly, the number of investors in the market, and, finally, the magnitude of profit opportunities available at the certain time. Therefore, as such opportunities shift, so too will the concerned investors. In proof of it, after 1998, the number of previously mentioned hedge funds declined dramatically because of outright failures, investor redemptions, and fewer startups (Lo, 2005), however many of them have reappeared in recent times and their performance has significantly improved.

The correlation of irrational investors is an assumption that plays a fundamental role in behavioral finance. To generate a deviation between the fundamental value and course, it is necessary that there are initially ignorant investors, mistaking the fundamentals. We can say about this assumption that this is partly a matter strictly empirical. Indeed, it may well be that, in a given situation specific, there are, in fact, on the market, investors uninformed or hunters' trend. However, the truly relevant theoretical question is to ask whether, as argued by behavioral finance, the presence of ignorant investors is a necessary condition for the inefficiency occurs. We know, for example, that the theory of rational bubbles answers this question in the negative way. This question deserves to be asked especially that the hypothesis that behavioral finance need not be reduced to the only presence of ignorant investors. It requires more, namely correlated ignorant investors around the same mistake. But how this theory can justify this surprising correlation? The error is inherently multifaceted, why a majority of agents "choose" the same?

To answer those questions we need the help of some works about the psychology of behavior in a situation of incertitude. We can summarize the arguments just using a citation of Shleifer "Remember that the second line of defense of the theory of efficient markets is to argue that irrational investors, although they may exist, exchange randomly and therefore exchanges cancel each other. This is an argument that theories of Kahneman and Tversky reject entirely. Empirical analyzes demonstrate precisely that people do not deviate from rationality randomly, but rather that most deviates in an identical way".

All experimental work on the stock market finds inefficiencies in these markets. This result should be seen as usual, when it focuses on procurement of goods, experimental economics advance very favorable results with efficiency ideas. The self-referential hypothesis (Orlean, 1999), to understand it easily, it is the idea that a rational investor should consider the general opinion of the market and abandoning the idea that the general opinion is the result of a collective irrationality. Instead, we must assume that all players are rational and they are also look at what the opinion of the market to determine the most profitable investment. Here we can find the intuition of Keynes's beauty famous contest, where price changes are due to an intuition where everyone tries to rationally anticipate what will be the market sentiment. This configuration is a complex interaction that can bring about a multiplicity of equilibriums.

\section{Conclusion}

The behavioral finance came with the emergence of the critics about the three hypotheses about the efficiency of the market. We saw in this paper that there are some controversies now between the Neoclassical and the main authors of the behavioral finance. Today, all the transactions and the decisions of the investors are still made with the neoclassical financial rules in the mind, but as we saw we may wonder how it will become in the next decade because the behavioral finance is winning importance every day. I'm not saying that it will give the keys and the models like the traditional theory, it is just a way of thinking which will more give you some information about the main players and how people will react in general. Finally, behavioral finance isn't something new or revolutionary, it's just the application of the psychology in to the financial sector.

We can say that every theory has its drawbacks but the mass of evidence promotes EMH. A huge part of students do agree that the markets are efficient. Of course, there are critics who suggest that EMH has some drawbacks and does not explain one or another fact which has occurred in the past decade. The most enduring critiques of the Efficient Market Hypothesis comes from economists and behaviorists who argue that such evidence as, predictability of market participants behavior, existence of stock price patterns, possibility to predict stock prices after performing fundamental analysis of a company, can prove that market prices are at least partially predictable. This would mean that new information is not the only factor that influences price changes. Although the paradigm of the AMH - an evolutionary framework reconciling many of the apparent contradictions between effcient markets and behavioral exceptions - might become a viable alternative to the $\mathrm{EMH}$, that was not supplanted by any other single alternative theory proposed before, however, it is important to stress out that evidence which are against EMH haven't passed their "test time" to prove that EMH can't defend its assumptions. And as for now, efficient market hypothesis remains to be the one which describes 
price changes and movements in financial markets.

\section{References}

Clarke, Jonathan, Jandik, Tomas, Mandelker, Gershon. The Efficient Markets Hypothesis [interactive]. [Previewed 22nd Oct 2013]. Access via the Internet: http://www.e-m-h.org/CIJM.pdf

De Long Bradford J., Andrei Shleifer, Lawrence H. Summers and Robert J. Waldmann, « NoiseTrader Risk in Financial Markets », Journal of Political Economy, vol. 98, n²4, 1990a, 703-738.

De Long Bradford J., Andrei Shleifer, Lawrence H. Summers and Robert J. Waldmann, « Positive Feedback Investment Strategies and Destabilizing Rational Speculation », TheJournal of Finance, vol. XLV, n², June 1990b, 379-395.

Deng, Min. Death of the Efficient Market Hypothesis [interactive]. 20th Australasian Finance \& Banking Conference 2007 Paper. [Previewed 25th Oct 2013]. Access via the Internet: http://papers.ssrn.com/sol3/papers.cfm?abstract_id=1006716

Dunbar Nicholas, Inventing Money. The Story of Long-Term Capital Management and theLegends Behind It, New York et Toronto, John Wiley \& Sons Ltd, 2000.

Fama Eugene, «Random Walks in Stock Market Prices», Financial Analysts Journal, vol.21, n5, September/October 1965, 55-59.

Fama Eugene, « Efficient Capital Markets: A Review of Theory and Empirical Work », Journal of Finance, vol. 25, 1970, 383-417.

Fama Eugene, « Efficient Capital Markets: Reply », The Journal of Finance, vol. 31, n²,March 1976, 143-145.

Fox, Justin. The Myth Of The Rational Market [interactive]. 2009, HarperCollins, New York, USA, pp. 382 [Previewed 24th Oct 2013]. Access via the Internet: http://www.fintp.hr/upload/files/ttp/2010/3/grguric2.pdf

Gourieroux Christian and Joann Jasiak, Microeconometrics of Individual Risks: Credit,Insurance and Marketing, Princeton University Press, 2006.

Kast Robert et André Lapied, Fondements microéconomiques de la théorie des marchés financiers, Paris, Economica, coll. « Gestion », 1992.

Landier Augustin and David Thesmar, Le grand méchant marché. Décryptage d'un fantasmefrançais, Paris, Flammarion, 2007.

Lo, Andrew W. Efficient Market Hypothesis. 2007 [interactive]. Massachusetts Institute of Technology (MIT) - Sloan School of Management. [Previewed 25th Oct 2013]. Access via the Internet: http://papers.ssrn.com/sol3/papers.cfm?abstract_id=991509

Lo, Andrew W. Reconciling Efficient Markets to Behaviour Finance: The Adaptive Markets Hypothesis. 2005 [interactive]. The journal of Investment Consulting - VOL. 7, NO. 2, 2005. [Previewed 23rd Oct 2013]. Accessvia the Internet:http://web.mit.edu/alo/www IPapers/JIC2005_Final.pdf

Lo, Andrew W. The Adaptive Markets Hypothesis. Market Efficiency from an Evolutionary Perspective. [interactive]. The Journal of Portfolio Management 30th Anniversary Issue, 2004. [Previewed 25rd Oct 2013]. Access via the Internet: http://web.mit.edu/alo/www/Papers/JPM2004_Pub.pdf

Malkiel Burton G., « The Efficient Market Hypothesis and Its Critics », Journal of EconomicPerspectives, vol. 17, n, hiver 2003, 59-82.

Mandelbrot Benoît, « Formes nouvelles du hasard dans les sciences », Économie Appliquée,vol. 26, 1973, 307-319.

Mehta Judith, Chris Starmer and Robert Sugden, « The nature of salience : An experimentalinvestigation of pure coordination games », American Economic Review, vol. 84, n², June 1994,658-673.

Gourieroux Christian and André Tiomo, Risque de crédit : une approche avancée, Paris, Economica, 2007.

Orléan André, Le Pouvoir de la finance, Paris, Éditions Odile Jacob, 1999.

Palan, Stefan. The Efficient Market Hypothesis and its Validity in Today's Markets. [interactive]. [Previewed 25th Oct 2013]. Access via the Internet: http://www.palan.biz/academic/documents/palan_2004-08_thesis-efficient_markets.pdf;

Robert J. Shiller From Efficient Market Theory to Behavioral Finance. Journal of Economic Perspectyves. Vol. 17, Nr. 1., 83-104

Shostak, Frank. In Defense of Fundamental Analysis:A Critique of the Efficient Market Hypothesis [interactive]. The Review of Austrian Economics, June 1997, pp. 27-46. [Previewed 22nd Oct 2013]. Access via the Internet: http://www.unz.org/Pub/RevAustrian Economics-1997q2-00027. 